\title{
Penatalaksanaan Perawatan Hiperpigmentasi Pada Gingiva Dengan Metode Scrapping Menggunakan Pisau Bedah: Studi Kasus
}

\section{Management of Hyperpigmentation Treatment in Gingiva with Scrapping Method Using Scalpel: Case Report}

\author{
Nita Nurniza ${ }^{1}$, Ina Hendiani ${ }^{2}$, Yanti Rusyanti ${ }^{2}$, Agus Susanto ${ }^{2}$ \\ ${ }^{I}$ Departemen Periodonsia, Fakultas Kedokteran Gigi Universitas YARSI, Jalan Letjen. Suprapto, \\ Cempaka Putih, Jakarta Indonesia 10510. Telepon (021) 4206674, 4206675, 4206676.. \\ ${ }^{2}$ Departemen Periodonsia, Fakultas Kedokteran Gigi Universitas Padjadjaran, Jl. Raya Bandung \\ Sumedang KM 21, Jatinangor Jawa Barat Indonesia 45363. Telepon: (022) 7794120
}

Email:nita.nurniza@yarsi.ac.id

KEYWORDS hyperpigmentation, gingiva, depigmentation.

ABSTRACT Hyperpigmentation is a disorder of the gingiva caused by various factors including heredity, disease, drugs, smoking habits. This can occur because of the accumulation of melanin pigment in the basal gingival layer resulting in a brownish or blackish color on the surface of the gingiva which when viewed aesthetically is not good because it is not like the normal gingival color of coral pink. Objective: to get the gingival color back to normal, namely coral pink. Management in cases of pigmentation using the surgical method by scrapping using a scalpel No.15. In this study there were 3 cases, namely, case 1, a 20-year-old female patient had genetic or genetic hyperpigmentation. Case 2, a 27-year-old male patient had genetic or genetic hyperpigmentation. Case 3, a 24-year-old female patient had gingival pigmentation due to smoking habits. The results of surgical management in all three cases, namely the gingival depigmentation method by scrapping gave a good esetetic result, but for gingival hyperpigmentation in cases 1 and 2 it could recur later.

\section{PENDAHULUAN}

Gingiva merupakan bagian dari jaringan periodonsium yang paling luar. Gingiva berfungsi sebagai pelindung tulang alveolar dan akar gigi sampai pada batas cementoenamel junction, barier terhadap faktor mekanik, kimia, selain itu gingiva memiliki peranan dalam hal estetika. Estetika sangat penting bagi sebagian orang terutama menyangkut profesi yang berhubungan atau berkomunikasi dengan orang banyak.
Salah satu masalah yang sering dilanda oleh sebagian orang adalah warna dari gingiva, hal ini dapat terjadi perbedaan warna gingiva pada berbagai suku/ras, namun warna gingiva yang normal dan sehat adalah coral pink. Warna pada gingiva berpengaruh terhadap penampilan seseorang sehingga sebagian orang menginginkan warna gingiva yang normal dan sehat (Ryan dkk, 2016; Kodir, 2014) 
Warna gingiva tergantung pada sel warna yang disebut dengan sel melanosit atau pigmen melanin yang berwarna coklat. Sel melanosit terutama terletak di lapisan sel basal dan suprabasal dari epithel. Pigmentasi merupakan kondisi pigmen melanin yang memiliki peran dalam pewarnaan secara endogen seperti tampak pada kulit, mukosa, rambut, mata dan bagian otak manusia. Dalam rongga mulut dikenal dengan pigmentasi oral yaitu perubahan warna mukosa mulut atau gingiva yang terkait dengan faktor eksogen dan endogen. Faktor eksogen antara lain kontak dengan logam berat, kebiasaan merokok. Faktor endogen yaitu penyakit gangguan pada endokrin dan genetik (Ryan dkk, 2016; Kasagani dkk, 2012)

Pigmen melanin yang terdapat pada mukosa berfungsi sebagai perlindungan dari efek negatif radiasi sinar ultraviolet. Paparan sinar ultraviolet dan durasi yang lama dapat menyebabkan pigmen melanin jumlahnya bertambah banyak. Pigmen melanin yang berlebihan oleh sel melanosit pada jaringan gingiva menyebabkan terjadinya hiperpigmentasi gingiva. Warna pigmen melanin dapat bervariasi dari terang ke gelap coklat atau hitam, tergantung pada jumlah dan distribusi melanin dalam jaringan (Ryan dkk, 2016; Kodir, 2014; Prasad dkk, 2010)

Tindakan untuk menghilangkan pigmentasi pada gingiva untuk mendapatkan estetika yang baik ada beberapa macam antara lain metode dengan tujuan untuk menghilangkan lapisan yang berpigmen yaitu metode bedah dan metode kimia. Metode bedah meliputi teknik bedah dengan pisau, abrasi, cryosurgery dan laser. Metode kimia dengan menggunakan bahan kimia yang telah digunakan untuk depigmentasi yaitu $90 \%$ fenol dan alkohol $95 \%$, tetapi metode ini sudah tidak digunakan lagi saat ini. Metode dengan tujuan menutupi/masking gingiva berpigmen meliputi Free Gingival Graft, Acellular Dermal Matrix Allografts (Kasagani dkk, 2012; Prasad dkk, 2010)

\section{METODOLOGI}

Pada setiap kasus menggunakan teknik depigmentasi gingiva menggunakan pisau bedah yaitu melibatkan pengangkatan epitel gingiva, bersama dengan lapisan jaringan yang mendasari, dan memungkinkan jaringan epitel tidak ada sehingga akan tumbuh jaringan epitel baru. Prosedurnya antara lain pertama dilakukan tindakan asepsis pada daerah operasi kemudian anastesi infiltrasi dengan obat anastesi pada mukobukal fold. Tahap selanjutnya dilakukan depigmentasi pada gingiva regio menggunakan pisau bedah No.15 dengan cara scrapping/mengikis lapisan epitelium sampai lapisan berpigmen dengan hati-hati. Kemudian setelah scrapping selesai dilakukan irigasi daerah operasi menggunakan larutan saline steril, dilanjutkan dengan pemasangan periodontal pack/periodontal dressing. Pada akhir operasi pasien diberikan instruksi paska operasi serta medikasi, dan diharuskan datang untuk kontrol 7- 10 hari paska operasi. (Prasad dkk, 2010; Deepa dkk, 2013; Kanakamedala dkk, 2010)

\section{S I}

Kasus 1, pasien perempuan usia 20 tahun, pekerjaan mahasiswa, dengan keluhan gusi bagian depan rahang atas dan rahang bawah berwarna coklat kehitaman serta merasa penampilannya terganggu. Pasien memiliki riwayat keluarga dengan kondisi gusi berwarna coklat kehitaman. Pasien tidak memiliki kebiasaan merokok. Pada pemeriksaan intraoral ditemukan karang gigi supragingiva, gigi crowding anterior, terdapat hiperpigmentasi pada 
regio $13-23,33-43$, diagnosis pada pasien ini adalah gingivitis marginal regio anterior bawah dan anterior atas. Hasil pemeriksaan darah dan pemeriksaan radiologi tidak ditemukan kelainan. Satu bulan sebelum dilakukan tindakan depigmentasi gingiva, pada pasien ini telah dilakukan skeling dan rootplaning satu bulan sebelum tindakan depigmentasi gingiva. Pada gambar 1 kondisi sebelum dilakukan tindakan depigmentasi dan gambar 2 tampak kondisi gingiva 2 minggu setelah dilakukan depigmentasi gingiva.
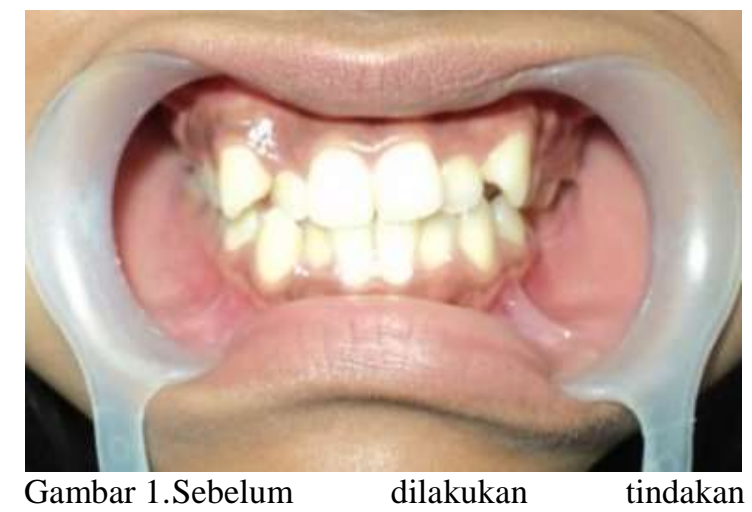
depigmentasi gingiva.

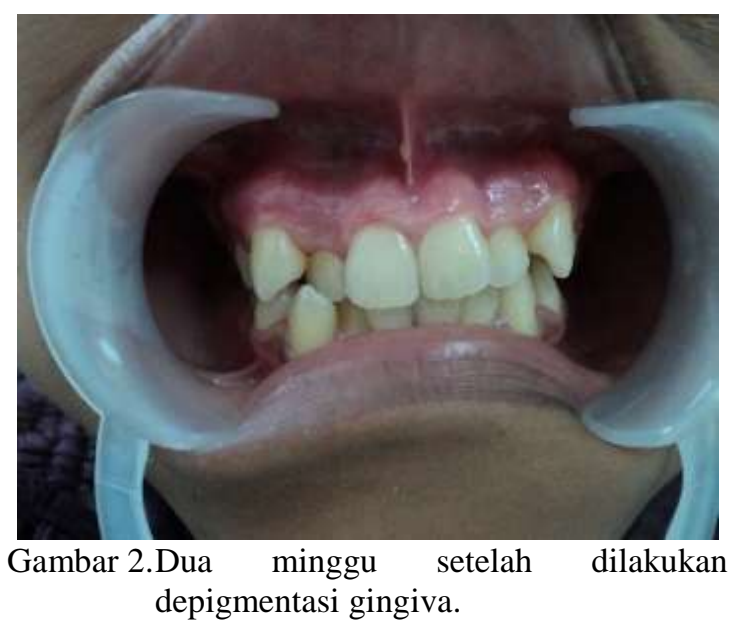

Kasus 2, pasien laki-laki berusia 27 tahun, pekerjaan administrative officer, dengan keluhan gusi terlihat hitam namun pasien tidak mengetahui sejak kapan gusi mulai hitam. Pada angggota keluarga lain terdapat gusi berwarna kehitaman. Pasien tidak mempunyai kebiasaan merokok. Pasien ingin gusinya berwarna merah muda kembali karena berhubungan dengan pekerjaan. Pada pemeriksaan intraoral ditemukan karang gigi supragingiva, terdapat hiperpigmentasi pada regio 13-23, 33-43, diagnosis pada pasien ini adalah gingivitis marginalis regio anterior bawah dan anterior atas. Hasil pemeriksaan darah dan pemeriksaan radiologi tidak ditemukan kelainan. Satu bulan sebelum dilakukan tindakan depigmentasi gingiva, pada pasien ini telah dilakukan skeling dan rootplaning. Pada gambar 3 tampak gingiva yang mengalami hiperpigmentasi dan belum dilakukan depigmentasi pada regio 13-23, 33-43 dan pada gambar 4 setelah dilakukan depigmentasi gingiva.
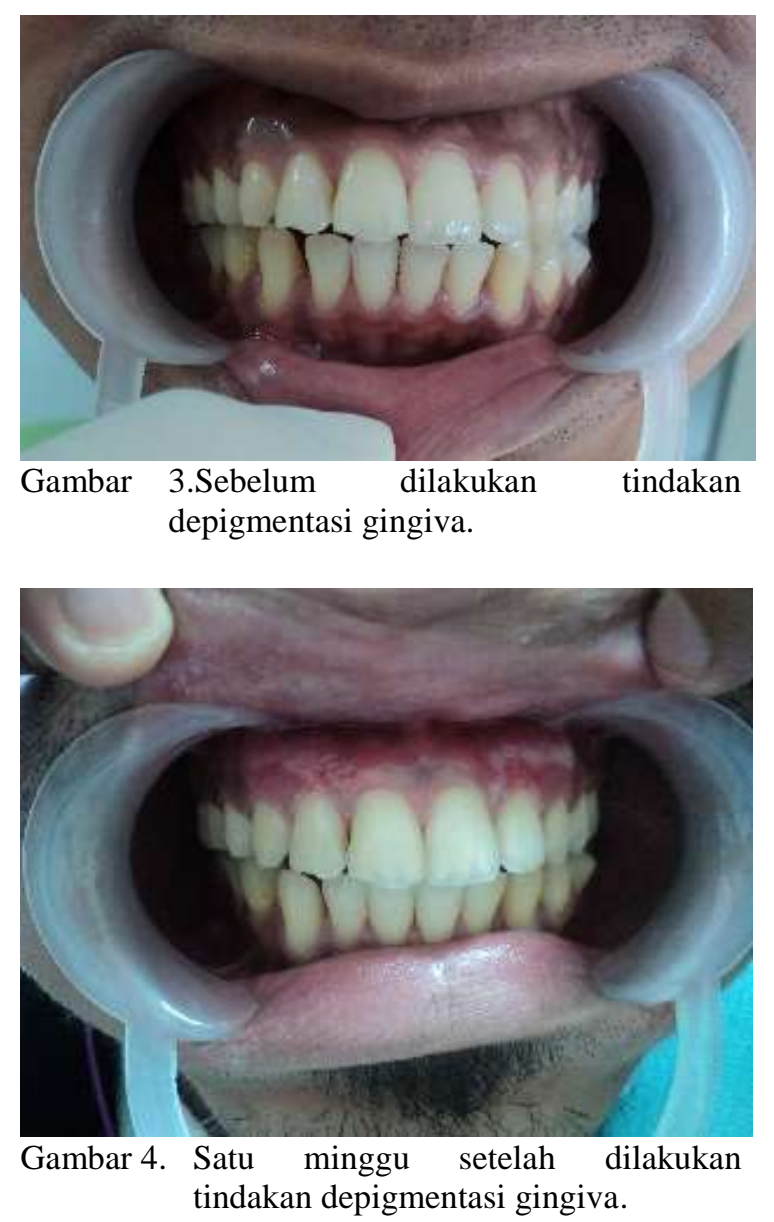
Kasus 3, pasien perempuan berusia 24 tahun, pekerjaan wiraswasta, datang dengan keluhan gusi berwarna hitam pada rahang atas dan rahang bawah. Keluhan itu dirasakan sejak \pm 3 tahun lalu. Pasien memiliki kebiasaan merokok \pm 5 tahun lalu sampai sekarang dengan konsumsi ratarata 1 bungkus rokok per hari. Pasien ingin gusinya terlihat merah muda kembali. Pada pemeriksaan intraoral ditemukan karang gigi subgingiva dan supragingiva, terdapat hiperpigmentasi pada regio 13-23, 33-43, diagnosis pada pasien ini adalah lokalisata regio 36. Hasil pemeriksaan darah dan pemeriksaan radiologi tidak ditemukan kelainan. Satu bulan sebelum dilakukan tindakan depigmentasi gingiva, pada pasien ini telah dilakukan skeling dan rootplaning. Pada gambar 5 terlihat gingiva yang mengalami hiperpigmentasi dan belum dilakukan depigmentasi pada regio 13-23, 33-43 dan pada gambar 6 setelah dilakukan depigmentasi gingiva.
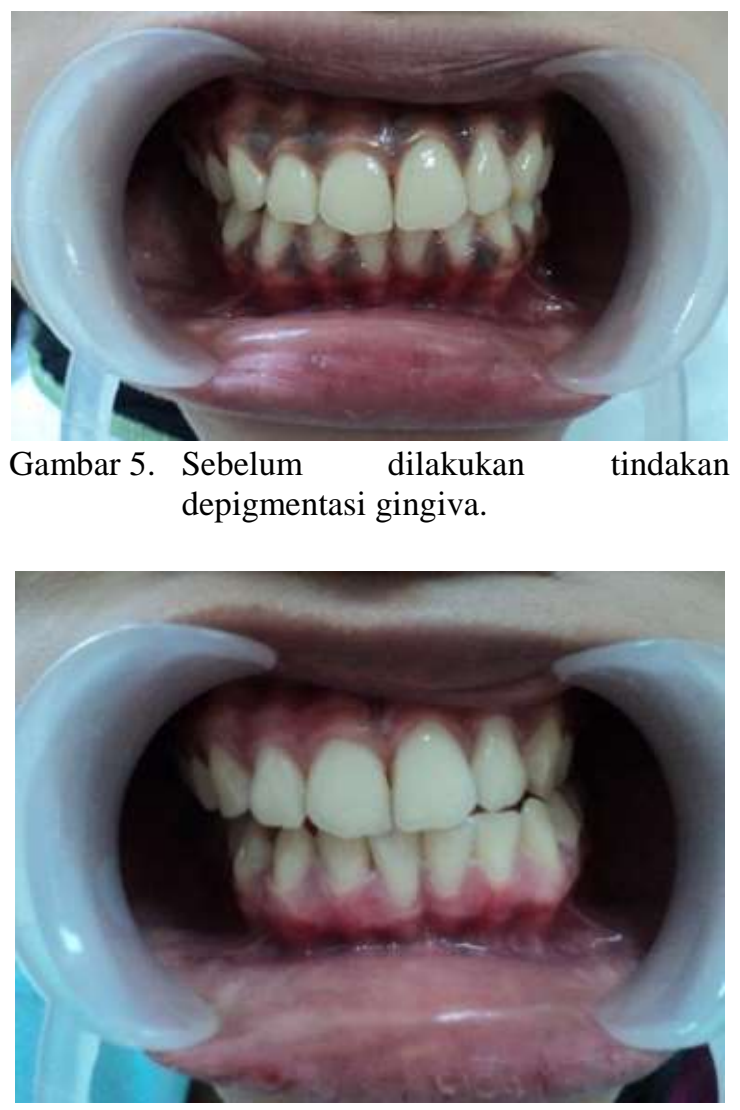

Gambar 6. Satu bulan setelah dilakukan tindakan depigmentasi gingiva.

Estetik merupakan masalah yang cukup menjadi pertimbangan beberapa orang. Dalam hal ini senyum memiliki peranan penting dalam berbagai kondisi, hal ini yang menimbulkan masalah bila saat senyum gingiva tampak berwarna kehitaman yang mengganggu penampilan karena tampak tidak normal, padahal dalam beberapa kasus gingiva berwarna kehitaman ini adalah hal yang alami. Pada studi kasus ini salah satu tindakan yang dilakukan dengan tujuan mengembalikan warna gingiva menjadi normal yaitu coral pink dengan cara menghilangkan warna pigmentasi yang disebabkan oleh melanin pada gingiva. (Kanakamedala dkk, 2010; Gulati dkk, 2016).

Melanin adalah pigmen coklat nonhemoglobin yang merupakan pigmen endogen yang paling umum. Pigmen ini diproduksi oleh sel melanosit yang ada di lapisan basal epitel. Peningkatan produksi melanin pada mukosa dapat disebabkan oleh berbagai faktor antara lain trauma, hormon, radiasi, dan medikasi. Pigmentasi melanin disebabkan oleh deposisi melanin oleh melanosit aktif yang terletak terutama di lapisan basal epitel rongga mulut. Pigmentasi fisiologis mukosa mulut secara klinis sebagai multifokal atau difus, pada orang yang berkulit gelap, gingiva dapat mengandung pigmen melanin lebih besar dari mukosa alveolar yang berdekatan. Jika gingiva gingiva memliki pigmentasi fisiologi dilakukan tindakan pembedahan, maka dapat gingiva dapat sembuh dengan sedikit atau tanpa pigmentasi. (Deepa dkk, 2013; Kanakamedala dkk, 2010; Gulati dkk, 2016). Teknik bedah menggunakan pisau bedah dengan cara scrapping untuk menghilangkan pigmentasi pada gingiva dapat menjadi pertimbangan bila terdapat kendala peralatan yang tidak memadai di klinik. Keuntungan lain menggunakan pisau bedah untuk depigmentasi gingiva 
adalah masa penyembuhan luka lebih cepat daripada teknik lainnya. Kekurangan penggunaan pisau bedah pada saat operasi adalah dapat menyebabkan perdarahan selama dan setelah operasi, dan hal ini dapat diatasi dengan menutup luka pada gingiva yang terbuka menggunakan periodontal pack/periodontal dressing selama 7 hingga 10 hari. (Ryan dkk, 2016; Kasagani dkk, 2012; Deepa dkk, 2013)

\section{PENUTUP}

Metode depigmentasi gingiva
menggunakan pisau bedah dengan
scrapping lapisan epitelium sampai lapisan
berpigmen memiliki hasil yang baik pada
ketiga kasus.

\section{DAFTAR PUSTAKA}

Deepa D, Chawla A, Srivastava P. 2016. Gingival Depigmentation by Scalpel, Diode Laser and Electrosurgery - A Case Report. Indian Journal of Dental Sciences. 5(1)

Gulati N, Dutt P, Gupta N, Tyagi P. Gingival Pigmentation: Revisited (Review Article). Journal of Advanced Medical and Dental Sciences Research. Vol. 4. Issue 1. Jan-Feb 2016.

\begin{abstract}
Kanakamedala AK, Geetha A, Ramakrishnan T, Emadi P. Management Of Gingival Hyperpigmentation By The Surgical Scalpel Technique - Report Of Three Cases. Journal of Clinical and Diagnostic Research [serial online] 2010 April [cited: 2010 April 5]; 4:2341-2346.
\end{abstract}

Kasagani SK, Nutalapati R, Mutthineni RB. Esthetic Depigmentation of Anterior Gingiva. A Case Series. The New York State Dental Journal. 78 (3):26-31·April 2012.

Kodir, AIA. ODONTO Dental Journal.Volume 1. Nomor 2. Desember 2014 http://jurnal.unissula.ac.id/index.php /odj/article/view/282/507 diunduh Selasa,14 Mei 2019.

Prasad SSV, N Agrawal, NR Reddy. Gingival Depigmentation: A Case Report. People's Journal of Scientific Research. Vol.3(1): 27-29. Jan 2010.

Ryan, M, Krismariono, A. Gingival Scraping untuk Depigmentasi Gingiva : studi kasus. MKGK. Desember 2016; 2(3): 172-175. ISSN: $\quad 2460-0059$ (online). https://jurnal.ugm.ac.id/mkgk/article/ download/33762/20248. Diunduh Selasa, 14 Mei 2019. 